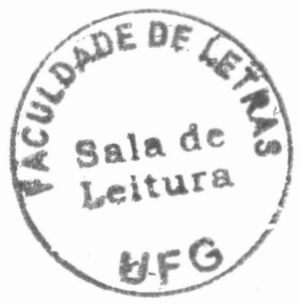

Artigos 
Revista da ANPOLL, n" 4, p. 11-37, jan./jun. 1998

\title{
O SIGNIFICADO DA ORDEM DOS PRONOMES POSSESSIVOS NO SINTAGMA NOMINAL*
}

\begin{abstract}
RESUMO: Este trabalho discute a relação entre as diferenças semânticas causadas pela anteposição ou posposição do pronome possessivo em relação ao núcleo nominal e o papel sintático e semântico do pronome nessas posições. A hipólese é que as diferentes posições do pronome possessivo eslão correlacionadas a diferentes funções sintálicas e semânticas: o pronome possessivo anteposto ao núcleo é argumental (sintalicamente, um sujeilo ou um complemento), já o pronome possessivo posposto ao núcleo é um predicado com a função sintálica de adjunto. Este trabalho também argumenta que o caráter delimilador do pronome possessivo anteposto não decorre de uma incorporação de um determinante definido. O falo de que o possessivo anteposto é um elemento dêilico em uma função argumental, faz com que a denotação do sintagma nominal ao qual pertence selecione um conjunto composto de elementos do contexto imediato e este conjunto é indistingüível dos elementos que o compõem. Essa ação delimitadora torna o artigo definido quase que redundante e os indefinidos quase que incompalíveis com a anteposição do pronome.
\end{abstract}

Ana Lúcia Müller**

PALAVRAS-CIIAVE: possessivos; sintagma nominal; sinlaxe; semânlica.

\section{OS TIPOS DE SINTAGMAS NOMINAIS POSSESSIVIZADOS NO PORTUGUÊS BRASILEIRO}

$\mathbb{N}$

esta seção, vou examinar c trazer a tona dados empíricos sobre a anteposição e a posposição do pronome possessivo ao núcleo nominal, apresentando e discutindo dados de dois corpora for-

* Este trabalho é uma versĩo do capítulo VII de Müller (1997). Agradeço a C. Franchi e a R. Ilari a leitura e comentários. Agradeço também aos participantes dos Seminários em 'leoria Gramatical do Departamento de Lingüística da USP pelos comentários, a maioria dos quais não foi possível incorporar por questão de tempo.

* * Universidade de São Paulo - USP. 
MÜlLLER, Ana Lúcia. O significado da ordem dos pronomes possessiros no sinlagma nominal.

mados a partir das gravações do Projeto NURC. O primeiro é o corpus mínimo do Projeto da Gramática do Português Falado ${ }^{1}$ examinado por Neves (1993) que se compóe das seguintes gravações do projeto NURC: SP 234, 360, 405; BA 049, 098, 231; RS 045, 278, 291; RJ 328, 355, 379; PE 005, 131, 337. O segundo é o corpus levantado por Franchi (1996b) que se compõe das seguintes gravações do projeto NURC: BA 95; PA 6, 120. 291, 266, 365; PE 4, 79, 151, 266, 279, 340, 782; RJ 158, 328 e SP 62, 137, 161, 208, 234, 242, 250, 251, 255, 333, 343, 360, 396. Os corpora se sobrepõem em quatro inquéritos, como se pode verificar.

O número de ocorrências de cada tipo de possessivo para os dois corpora está expresso na tabela 1. A freqüência da ocorrência do pronome possessivo posposto ao núcleo nominal é baixa - 5,19\% e $6.33 \%$ - nos respectivos corpora.

\begin{tabular}{|l|c|c|cc|}
\hline \multicolumn{5}{|c|}{ Tabela 1 } \\
Ocorrências do pronome possessivo anteposto versus \\
ocorrências do pronome possessivo posposto ao núcleo nominal. \\
\hline
\end{tabular}

Fonte: Neves (1993) e Franchi (1996).

1 Para maiores detallhes sobre o Projeto NURC ver Castilho \&. Preti (1986) e para maiores detalhes solhe o Projeto da Cramática do Português Fàlado, ver Castillho (1990:19). 


\subsection{O PRONOME POSSESSIVO ANTEPOSTO AO NÚCLEO NOMINAL}

Neves (1993) estabelece um quadro empírico geral da ordem dos elementos do sintagma nominal possessivizado encontrado no corpus mínimo do Projeto da Gramática do Português Falado, tanto para o pronome possessivo anteposto ao nome quanto para o pronome possessivo posposto ao nome. Na tabela 2, reproduzo seus resultados para o possessivo anteposto e de (1)(6) exemplifico os tipos de determinantes que ocorrem neste caso ${ }^{2}$.

\begin{tabular}{|c|c|c|c|c|}
\hline \multicolumn{5}{|c|}{ Tabela 2} \\
Ordem dos elementos do SN possessivizado com o \\
possessivo anteposto ao substantivo. \\
\hline 1 & 2 & 3 & 4 & 5 \\
\hline todo/ $\phi$ & $\begin{array}{c}\text { artigo } \\
\text { definido/art. } \\
\text { Indefinido/[ }\end{array}$ & POSSESSIVO & $\begin{array}{c}\text { numeral ordinal/ } \\
\text { quantificador } \\
\text { indefinido/ } \\
\text { outro/próprio/ } \\
\phi\end{array}$ & NOME \\
\hline
\end{tabular}

Fonte: Neves (1993): 170.

(1) cla faz a feira junto com a minha tia (DID-RJ-328)

(2) esse nosso cineminha... artesanal... foi liquidado (EF-SP-153)

2 Estou usando o termo determinante como na Teoria dos Quantificadores Ceneralizados para todos os elementos com função delimitadora no sintagma nominal (cf. Barwise \&. Cooper, 1981). As ocorrências (1)-(6) foram retiradas de Neves (1993). 
MÜLLER, Ana Lúcia. O significado da ordem dos pronomes possessivos no sintagma nominal.

(3) você vai resolve o que tem de resolver... e volta pra sua família (D2-RE-05)

(4) um filho de uma minha amiga entrou ... na Politécnica (DID-SP-242)

(5) ele deve procurar o seu sindicato ... a fim de que possa... ver:todos os seus problemas resolvidos (DID-RE-131)

(6) eu... fui para um colégio ... fiz meu primeiro ano (DII)-SP-242)

Franchi (1996) encontra os mesmos tipos de determinante com os possessivos antepostos ao núcleo em um corpus mais extenso. Seus resultados estão expostos na tabela 3 que, além de mostrar o tipo de determinante que ocorre com o pronome anteposto, indica também a percentagem de ocorrência de cada um desses tipos.

\section{Tabela 3}

Ocorrência de determinante antes do grupo pronome

\begin{tabular}{|l|c|c|c|c|c|c|}
\hline & $\phi$ & $\begin{array}{l}\text { artigo } \\
\text { definido }\end{array}$ & $\begin{array}{l}\text { demons- } \\
\text { trativo }\end{array}$ & todo(s) & um & Total \\
\hline $\begin{array}{l}\text { Ocorrên- } \\
\text { cias }\end{array}$ & 361 & 685 & 14 & 3 & 1 & 1064 \\
\hline $\begin{array}{l}\text { Percen- } \\
\text { tual }\end{array}$ & $33.89 \%$ & $64.37 \%$ & $1.31 \%$ & $0.28 \%$ & $0.09 \%$ & $100 \%$ \\
\hline
\end{tabular}

Fonte: Franchi (1996). 
As percentagens de Neves (1993) são bastantes próximas às de Franchi (1996b) e estão apresentadas na tabela 4.

\begin{tabular}{|c|c|c|c|}
\hline \multicolumn{4}{|c|}{ Tabela 4 } \\
Ocorrência de determinante antes do grupo \\
pronome adjetivo possessivo + nome no corpus mínimo. \\
\hline & artigo definido & $\phi$ & outros \\
\hline TOTAL & 251 & 130 & 4 \\
\hline PERCENTACEM & $65.19 \%$ & $33.77 \%$ & $1.04 \%$ \\
\hline
\end{tabular}

Fonte: Quadro 7, Neves (1993), anexo.

Como se vê os resultados dos dois levantamentos são extremamente próximos. No caso dos pronomes possessivos antepostos, predominam amplamente as construções [ART. DEFINII]O + POSS. + N] e [f+ POSS. $+\mathrm{N}$ ]: mais de $98 \%$ das ocorrências em ambos os corpora. Se considerarmos, como Franchi (1996b), ocorrências de |todo + artigo definido $+\mathrm{N}$ | como incluídas no caso do pronome precedido pelo artigo definido, há uma baixíssima percentagem de ocorrências ${ }^{3}$ de construções com o quantificador todo (as ocorrências (7) e (8) abaixo) e mesmo estas podem ser casos de contração do quantificador com o artigo definido.

(7) Nós moramos quase toda nossa vida no bairro de Vila Mariana (NURC-SP-208)

(8) Nós gostaríamos que o senhor contasse pra gente todo seu ciclo de vida (NURC-SP-208)

Os dados das tabelas 3 e 4 mostram que a anteposição do pronome

3 As ocorrências (7)-(11) foram retiradas de Franchi (1996). 
MÜLLER, Ana Lúcia. O significado da ordem dos pronomes possessivos no sinlagma nominal.

ao núcleo nominal é de alguma forma incompatível com a indefinitude. Na verdade, (4) é a única ocorrência de determinante indefinido com o pronome anteposto em ambos os corpora. Por outro lado, ocorrências como (2) acima e (9) e (10) abaixo, onde temos um demonstrativo precedendo o possessivo indicam, entretanto, que o pronome possessivo anteposto não é exatamente equivalente a uma "relação de posse + artigo definido", pois o artigo alterna com demonstrativos (além, evidentemente, de alternar com o vazio).

(9) Esse fato, a ânsia de lucro por causa daquela nossa distorsão econômica, os pulos que a nossa economia deu, não tem feito com que prospere (NURC-PA-06)

(10) Este meu sítio representa para mim, se outras coisas não houvessem, uma razão a mais para viver (NURC-SP-255)

Por outro lado, uma sentença como (3) acima nos mostra que, nem sempre, a anteposição implica em (ou pressupõc) a existência ou referencialidade do sintagma nominal possessivizado, pelo menos num sentido estrito, pois essa sentença pode ser entendida como uma sentença hipotética: "no caso de você ter família, você vai resolve... e volta... ". O mesmo fato se coloca para (11) na qual minhas amizades não aponta necessariamente para amigos determinados, mas possui um significado abstrato do tipo fazer amizades.

(11) [Passei meus anos todos naquele ambiente escolar.] Fiz minhas amizades, conheci professores (NURC-BA-231) 


\subsection{O PRONOME POSSESSIVO POSPOSTO AO NÚCLEO NOMINAL}

Na tabela 5, apresento os dados de Neves (1993) para a ordem dos elementos no sintagma nominal com o possessivo posposto e os enunciados entre (12) e (17)+ ilustram os tipos de modificadores que ocorrem com o pronome possessivo posposto.

\begin{tabular}{|c|c|c|c|}
\hline \multicolumn{4}{|c|}{ Tabela 5 } \\
Ordem dos elementos do SN com o possessivo \\
posposto ao substantivo \\
\hline 1 & 2 & 3 & 4 \\
\hline $\begin{array}{c}\text { definidores/ } \\
\text { artigo indefinido/ } \\
\text { qualquer/ } \\
\phi\end{array}$ & $\phi$ & NOME & POSSESSIVO \\
\hline$\phi$ & & & \\
\hline
\end{tabular}

Fonte: Neves,1993:171.

(12) a televisão nossa está se fazendo na medida ... ah justamente do que é a nossa sociedade (I)2-SP-333)

(13) I 12 eu estou sempre correndo estou sempre falando tudo depressa porque não dá tempo...

L1 é... se impôs

I 2 Tse a gente for parar...

L1 essa atitude sua...

L2 é ... (risos) exatamente se a gente for parar para fazer as coisas (D2-SP-360)

(14) uma tia minha lá... que matou a cobra (DID-POA-45)

4 As ocorrências (12)-(17) foram retiradas de Neves (1993). 
MÜLLLER, Ana Lúcia. O significado da ordem dos pronomes possessivos no sintagma nominal.

(15) você precisa sair um pouquinho para ir fazer qualquer negócio seu particular (DID-SP-62))

(16) eu acho que primeiro por incapacidade minha (D2-RJ-355)

(17) cu não me lembro quem cra o escritor cram três escritores nossos (D2-SP-333)

Os dados relativos à percentagem de ocorrências dos tipos de determinantes nos sintagmas nominais com possessivos pospostos apresentam uma maior variação. Na tabela 6 , mostro a distribuição obtida por Neves (1993) dos possessivos pospostos em relação à presença de outros determinantes no sintagma nominal.

\section{Tabela 6}

Ocorrência de determinante antes do grupo nome + pronome adjetivo possessivo no corpus mínimo.

\begin{tabular}{|c|c|c|c|c|}
\hline \multicolumn{2}{|c|}{ DEFINIDORES } & \multicolumn{2}{c|}{ NÃO-DEFINIIDRES } & $\phi$ \\
\hline $\begin{array}{c}\text { artigo } \\
\text { definido }\end{array}$ & demonstrativos & $\begin{array}{c}\text { um (numeral } \\
\text { ou indefinido) }\end{array}$ & qualquer & \\
\hline 2 & 1 & 8 & 1 & 9 \\
\hline $15.38 \%$ & $7.69 \%$ & $61.54 \%$ & $7.69 \%$ & \\
\hline
\end{tabular}

Fonte: Quadro 9, Neves (1993):176.

E na tabela 7, apresento a distribuição obtida por Franchi (1996). As percentagens obtidas por ambos são novamente bastante próximas e os dados de Franchi (1996) legitimam as percentagens obtidas por Neves (1993), cujo corpus era extremamente restrito no caso dos pronomes possessivos pospostos. 


\section{Tabela 7}

Ocorrência de determinante antes do grupo nome + pronome adjetivo possessivo no corpus de Franchi (1993b).

\begin{tabular}{|l|c|c|c|c|}
\hline & $\begin{array}{c}\text { Indef. }+\mathrm{N}+ \\
\text { Poss }\end{array}$ & $\begin{array}{c}\phi+ \\
\mathrm{N}+\text { Poss. }\end{array}$ & $\begin{array}{c}\text { Defin. }+\mathrm{N}+ \\
\text { Poss }\end{array}$ & Total \\
\hline Ocorrências & 44 & 8 & 20 & 72 \\
\hline Percentual & $61.11 \%$ & $11.11 \%$ & $27.77 \%$ & $100 \%$ \\
\hline
\end{tabular}

Fonte: Franchi (1996).

A quase total ausência de indefinidos com o pronome anteposto é aqui complementada pela alta percentagem de ocorrências de indefinidos (mais de 60\%) com o pronome possessivo posposto ao núcleo nominal. Não há, entretanto, uma complementariedade completa do tipo: anteposição e definitude versus posposição c indefinitude. Uma percentagem significativa - 23,07\% c $27.77 \%$ - de definidores ocorre com o pronome possessivo posposto, como na ocorrência (12) acima e nas ocorrências (18) e (19) abaixo 5 .

(18) [falando do filho do destinatário] Você trata bem o menino seu que tem sarampo enquanto que os outros não são bem tratados (NURC-PE-151)

(19) Eu acho que a Marília tem uma força dramática muito grande o que faz (com) que se suponha ncla uma atriz dramática que não foi aproveitada. É tão raro que o ator nosso tenha esses dois predicados (NURC-SP-333)

Os dados empíricos desta seção mostram que existem questões intrigantes sobre as diferenças entre os pronome possessivo quando antepos-

5 Ocorrências retiradas de Franchi (1996). 
MÜlLLER, Ana Lúcia. ( ) significado da ordem dos pronomes possessivos no sintagma nominal.

to ao nome e o pronome possessivo quando posposto ao nome: (i) a existência de algum tipo de "incompatibilidade" entre a anteposição do pronome e a indefinitude; (ii) a preferência esmagadora pela definitude do pronome possessivo anteposto que, no entanto, não corresponde a uma incompatibilidade entre posposição e definitude.

\section{A SEMÂNTICA DA ORDEM DOS PRONOMES POSSESSIVOS NO SINTAGMA NOMINAL}

Esta seção tem por objetivo discutir a diferença semântica entre o pronome possessivo anteposto ao núcleo nominal e o pronome possessivo posposto a esse núcleo. Borges Neto (1978) parte de uma comparação entre sintagmas nominais contendo formas genitivas como nas sentenças em (20) e sintagmas nominais contendo pronomes possessivos como nas sentenças em (21). O autor faz notar que existem duas quebras no paralelismo existente entre os grupos de sentenças em (20) e (21). Estas podem ser percebidas imediatamente pela própria forma como foram alinhadas as sentenças ${ }^{6}$.

(20) a. O livro de Pedro é encadernado

b. Um livro de Pedro é encadernado

c. Livro de Pedro é encadernado

(21) a. O meu livro é encadernado

b. Um livro meu é encadernado

c. Livro meu é encadernado

A primcira é uma quebra no paralelismo formal entre as sentenças (a). Os sintagmas nominais "o livro de Pedro" e "o meu livro" possuem

6 As sentenças cm (20) e (21) são de Borges Neto (1978). 
Revisla da ANPOLL, no 4, p. 11-37, jan./jun. 1998

significados paralelos, ambos, numa situação de uso, tem a capacidade de apontar para um determinado livro, de realizar uma referência. Suas formas, entretanto, divergem, pois em (20) (a) a forma genitiva possessiva de Pedro encontra-se posposta ao nome, ao passo que em (21) (a) o pronome possessivo encontra-se anteposto ao nome. Todos os outros casos são paralelos: a forma indicadora de posse, genitiva ou pronominal, encontra-se posposta ao nome?

A segunda quebra no paralelismo entre os grupos de sentenças (20) c (21) é uma assimetria no comportamento de seus significados. A um paralelismo formal criado pela presença versus ausência do artigo definido entre os sintagmas nominais "o livro de Pedro" c "o meu livro", e os sintagmas nominais "livro de Pedro" c "meu livro", não corresponde um paralelismo entre seus significados. A omissão do artigo no sintagma nominal com pronome possessivo anteposto não causa qualquer alteração aparente em seu significado (o meu livro x meu livro). Já a omissão do artigo no sintagma nominal com a forma genitiva não pronominal posposta, causa uma mudança radical $\mathrm{em}$ seu significado. Segundo o autor, em (20) (a) e (b) e (21) (a) e (b) o predicado "ser cncadernado" é atribuído a uma entidade - algum livro determinado - o mesmo ocorrendo se o artigo é omitido em (21) (a). Já em (20) e (21) (c) este predicado é atribuído à classe não contextual "livro de Pedro".

O autor aponta para o fato de que quando anteposto ao nome o possessivo funciona equivalentemente ao artigo definido, delimitando além de predicar do - a classe determinada por este nome. Por outro lado, o pronome possessivo posposto ao nome possui um valor apenas predicativo, sendo a delimitação realizada pela presença de quantificadores ou do artigo indefinido. Daí decorreria a agramaticalidade das sentenças em (22), onde se tenta delimitar uma classe já previamente delimitada pela

7 O autor considera agramaticais ou, no mínimo, pedantes as sentenças "o livro meu é encadernado"e "um meu livro é encadernado".

8 Borges Neto define rapidamente como "náo contextual" uma classe genérica, não enumerável. 
MÜLL LER, Ana L Lúcia. O significado da ordem dos pronomes possessivos no sintagma nominal.

anteposição do possessivo. $\mathrm{O}$ autor conclui propondo a hipótese de que o possessivo anteposto ao nome tem um valor delimitativo (scmelhante ao dos artigos, quantificadores e demonstrativos) e que o possessivo posposto tem o valor de um predicado aplicado ao nome (semelhante ao dos adjetivos).

(22) * ${ }^{\top}$ lodo/qualquer/cada meu filho praticará esporte

As conclusões de Borges Neto são coerentes com a incompatibilidade encontrada nos dados empíricos entre a indefinitude e a anteposição do pronome possessivo. No entanto, a questão precisa ser melhor compreendida. De que mancira seriam causados os efeitos de sentido para os quais Borges Neto chama a atenção? A linha sugerida pelo artigo é a de que as diferenças de interpretação resultantes da anteposição e da posposição do pronome possessivo seriam causadas pelo fato de que o pronome possessivo anteposto ao núcleo nominal incorpora, de alguma maneira, um papel delimitador semelhante ao do artigo definido. Vou examinar essa questão mais de perto.

Um primeiro passo dentro da discussão mais geral é caracterizar o que se quer dizer ao se opor o caráter delimitativo ao caráter predicativo do pronome possessivo. Vou iniciar a discussão sobre o que seria uma operação de delimitação e uma operação de predicação citando Franchi (1996):

"No primeiro texto em (que vi) que se utiliza a contraposição entre esses dois termos é o de Manfred Bierwish (1970). Embora em termos ainda muito gerais, Bierwisch contrapõe os dois "tipos de elementos semânticos" da seguinte forma: Em relação a uma variável referencial $X_{i}$,

(...) o primeiro /delimitativo: artigos, quantificadores e outros formativos/ delimita o conjunto a que lal variável seja capaz de substituir, e o segundo representa as propriedades e relações que se prediquem dos elementos de conjunto delimilado. (...) 
Revista da ANPOLL, n 4, p. 11-37, jan./jun. 1998

Os traços delimilativos possuem estatuto completamente distinto dos traços predicantes: enquanto estes especificam condições que devem salisfazer os objelos do conjunto a que se faça referência, os delimilantes não se aplicam aos objetos como tais, mas ao conjunto tomado globalmente, especificando seu tamanho (relalivo ou absoluto), seu papel no discurso, elc. (Bierwish, op. cit.)

Para recuperar a intuição que está por trás disso, poderíamos dizer que se contrapõe dois distintos modos de fixar o "universo do discurso" sobre que deve operar a interpretação na identificação das denotações: os traços predicativo-descritivos funcionam como propriedades características (condições de pertinência que devem satisfazer quaisquer objetos para que sejam tomados como objetos do conjunto); os traços delimitativos como operações que associam conjuntos predicativamente caracterizados a sub-conjuntos relevantes (discursivamente?) para outras predicações."

Recolocando a questão em termos de nossos pronomes possessivos, penso que se podería dizer que o caráter delimitativo que se percebe no funcionamento do pronome possessivo anteposto ao núcleo nominal reflete o fato de que a anteposição de um pronome possessivo a um núcleo nominal parece realizar uma operação sintática que, de alguma forma, transforma este nome em um sintagma nominal pleno e uma operação scmântica que transforma um predicado (o nome) em um argumento (o sintagma nominal) ${ }^{9}$. Ou, dito de uma outra mancira, o constituinte [Poss [N]| ć passível de ser tomado como argumento de um outro predicado. Vou tentar concretizar a questão, discutindo uma sentença extremamente simples como meu gato dorme, cuja estrutura sintática está esquematizada em (23).

(23) $\left.I_{\mathrm{S}} \Gamma_{\mathrm{SN}} \mathrm{meu}\right|_{\mathrm{N}}$ gato $\left.]\right\rceil I_{\mathrm{SV}}$ dorme $] \mid$

Sintaticamente, temos o nome comum gato que ao se unir ao pronome possessivo теи forma um sintagma nominal o qual é passível de ser tomado como sujeito (um argumento, agora, no sentido sintático) do

9 Estou usando muitas vezes o termo sintagma nominal para significar todo o sintagma de determinante, por ser aquele o termo mais usual. 
MÜLLER, Ana Lúcia. O significado da ordem dos pronomes possessivos no sintagma nominal.

sintagma verbal (ou, mais precisamente, do sintagma flexional) dorme. Semanticamente, temos que o predicado gato é, de alguma forma, "delimitado" pelo pronome meu: a expressão meu gato denotaria não mais um conjunto, mas a entidade "meu gato", a qual pode ser tomada como argumento de um novo predicado, no caso, "dormir". Pensando em uma interpretação na qual sintagmas como gato e dormir denotam conjuntos de entidades, ao formar o constituinte meu gato, estaríamos "delimitando" - determinando - uma entidade que pertence ao conjunto dos gatos, da qual, por sua vez, é afirmado o fato de pertencer ao conjunto das entidades que dormem.

Penso que essa descrição do carater delimitativo do possessivo anteposto é fiel ao artigo de Borges Neto. No entanto, ao se descrever o possessivo anteposto dessa forma, perde-se o fato de que, mesmo quando anteposto, o possessivo também possui um caráter predicativo, indicando a existência de algum tipo de relação semântica entre o significado do nome c significado do pronome pessoal ${ }^{10}$. No caso da sentença (23), essa relação seria a relação de posse entre $\|$ o gato $\|$ e $\|$ eu $\|^{11}$. Perde-se também a possibilidade de explicar por que nem sempre |Poss |N|| equivale a |artigo definido $\mid$ Poss $\left.|\mathrm{N}|\right|^{12}$.

A limitação de uma caracterização do pronome possessivo apenas como um 'delimitador' fica patente quando se tenta explicitar o tipo de delimitador que ele seria, pois, se é verdadeira a análise de Borges Neto, o pronome possessivo quando anteposto ao nome, de alguma forma, incorpora o artigo definido. No entanto, é evidente que meu gato não equivale a o gato, mas sim a o meu gato.

Vamos examinar essa questão sob a luz de uma teoria semântica mais sofisticada como a Teoria dos Quantificadores Ceneralizados ${ }^{13}$ (cf.

10 R. Ilari (comunicação pessoal) me chamou atenção para esta questão. Deve-se observar também que nem Borges Neto, nem Franchi negam que o possessivo anteposto possui um caráter predicativo.

11 Estou usando a notação || ||, como tradicionalmente em semântica formal, para significar a denotação do item lingǘstico contido nos colchetes duplos

12 Esta questão será discutida mais adiante.

13 Minha descrição do funcionamento da T'eoria dos Quantificadores Ceneralizados hascia-se principalmente en Franchi (1996), Peres (1991) e Bach (1989). 
Barwise \& Cooper, 1981). Um determinante - um "delimitador", como $o$, um, todo, ... - é uma função que toma predicados (nomes) como argumentos e gera quantificadores generalizados (sintagmas nominais) como seus valores. Em outros termos, um determinante é uma função que toma conjuntos (a denotação dos nomes) como argumentos e gera conjuntos de conjuntos (a denotação dos sintagmas nominais) como valores. Um quantificador generalizado (cuja denotação é um conjunto de conjuntos), por sua vez, é uma função que toma conjuntos (denotações de sintagmas verbais) como argumentos e gera valores de verdade (denotações de sentenças). Esquematicamente em $(24)^{1+}$ :

$$
\begin{gathered}
\text { Nome } \\
\text { [Lconjunto de objetos]] }
\end{gathered}
$$

determinante

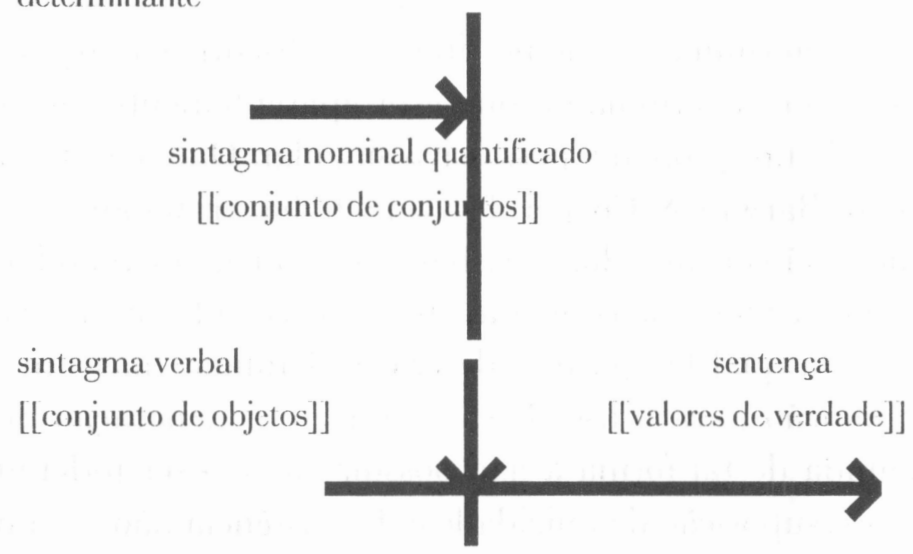

Vou ilustrar o funcionamento desta teoria com a sentença todo gato dorme. Gato e dormir denotam respectivamente o conjunto das entidades que são gatos e o conjunto das entidades que dormem. Todo denota uma função que toma o predicado 'gato' como argumento e tem como valor o 14 O esquema em (24) me foi sugerido por Rodolfo llari (comunicação pessoal). 
MÜLLER, Ana Lúcia. O significado da ordem dos pronomes possessivos no sintagma nominal.

quantificador generalizado 'todo gato' que denota o conjunto de todos os conjuntos que contêm o conjunto dos gatos, ou seja, [|todo gato]] contém o conjunto dos mamíferos, o conjunto dos animais domésticos, o conjunto dos mortais, o conjunto das entidades que gostam de peixe, ... . Todo gato, por sua vez, é uma função que toma o predicado 'dormir' como argumento e gera o valor de verdade Verdadeiro. Uma sentença como todo gato dorme é analisada como afirmando que a denotação de dormir, i.c., o conjunto das entidades que dormẹm, pertence à denotação de todo gato, i.e., ao conjunto de todos conjuntos que têm o conjunto dos gatos como membro. Em outras palavras, o conjunto das entidades que dormem é um dos conjuntos contido no conjunto de conjuntos [| todo gato]]. Note-se que toda esta seqüência de operações semânticas respeita a estrutura sintática da sentença: Determinante + Nome $=$ Sintagma Nominal e Sintagma Nominal + Sintagma Flexional = Sentença.

Mas o determinante que nos interessa discutir é o artigo definido, pois é esse determinante que está aparentemente incluso na anteposição de um pronome possessivo singular. O artigo definido é analisado por Barwise \& Cooper(1981) na linha strawsoniana, como pressupondo, não afirmando, a existência e a unicidade do referente: a unicidade não é tomada como uma parte das condições de verdade da sentença da qual faz parte a descrição definida, mas sim como uma precondição para o uso dessa descrição. A denotação de o é, então, definida de tal forma a não possuir valor - ser indefinida quando a pressuposição de unicidade e de existência não se cumpre. A formalização desta idéia está expressa em (25) (a) que é equivalente a (25) (b) (cf. Peres, 1991).

(25) a. $[\lceil o]](\mathrm{A})=[[$ todo $]]$ (A) se \#A=1; indefinido nos outros casos. $^{15}$

$15 \mathrm{O}$ símbolo \#A significa "o cardinal de $\mathrm{A}$ ", ou seja, o número das entidades contidas no conjunto $\mathrm{A}$. 
b. $\llbracket[\mathrm{o}]\rceil(\mathrm{A})=\{\mathrm{X} \subseteq \mathrm{E}: \mathrm{A} \subseteq \mathrm{X}\}$ se $\# \mathrm{~A}=1$; indefinido nos outros casos; onde E é o conjunto de indivíduos do universo e A é um Nome qualquer.

A equação em (25) (b) diz que a aplicação do Determinante $o$ a um Nome A resulta num conjunto $\mathrm{X}$ e esse $\mathrm{X}$ é um conjunto formado por todos os conjuntos que contêm A. Note que a intersecção de todos os conjuntos contêm A é obrigatoriamente um conjunto unitário porque [[o]] (A) é indefinida para os casos em que A tenha um número de membros diferente da unidade. $\mathrm{O}$ artigo definido no sintagma o gato, por exemplo, é interpretado então como uma função que toma o conjunto dos gatos, no caso um conjunto unitário, como argumento, e tem como valor o conjunto de todos os conjuntos que contêm esse conjunto unitário. A denotação de $O$ gato está formalmente expressa $\mathrm{cm}(26)$.

(26) $[[o] \|(\|$ gato $])=\{X \subseteq \mathrm{E}: \mathrm{G} \subseteq \mathrm{X}\}$ se $\# \mathrm{C}=1$; indefinido nos outros casos; onde $\mathrm{G}$ é o conjunto dos gatos.

Como ficaria uma análise do sintagma nominal possessivizado na Teoria dos Quantificadores Generalizados? Franchi (1996b) esboça uma proposta na qual considera o pronome como cumprindo um papel de elemento delimitador. Tento explicitar seu funcionamento na interpretação do sintagma meu gato $\mathrm{em}(27)$.

(27) $[[$ meu $]\rceil([\mid$ gato $])=\{\mathrm{X} \subseteq \mathrm{E}:[[$ gato $]] \cap[[\mathrm{meu}]] \subseteq \mathrm{X}\} ; \#$ (gato C. meu) $=1$, indefinido nos outros casos.

A equação em (27) diz literalmente que a denotação de meu gato é um conjunto $\mathrm{X}$ contido no conjunto de indivíduos do universo $\mathrm{E}$, formado pelos conjuntos que contêm a intersecção entre o conjunto dos gatos e o conjunto das coisas que são minhas e o conjunto determinado pela inter- 
MÜLLER, Ana Lúcia. O significado da ordem dos pronomes possessivos no sintagma nominal.

secção entre [|gato]| e [|meu]| só está definido para o caso desta intersecção determinar um conjunto unitário.

Já o pronome possessivo posposto é interpretado como tendo apenas um caráter predicativo. Gato meu é um nome comum que denota o conjunto intersecção entre [|gato]| e [|meu]]. Citando novamente Franchi (1996b):

"O que é interessante notar é que o procedimento explicativo leva a distinguir claramente o papel delimitativo do possessivo (que incorpora precondições pressuposicionais) da propriedade que o possessivo expressa (sua "face" predicativa) caracterizada como a interseção $A \cap B, c m$ que A corresponde à propriedade expressa pelo nome comum e B à propricdade expressa pelo possessivo.

Nesse sentido, a interpretação da expressão gato meu cm (28) seria bem distinta da denotação de meu gato c não se pode falar de pressuposição de unicidade e de existência. Sintaticamente gato meu é ainda um Nome que pode ser determinado, não um quantificador generalizado como, por exemplo, um gato meu.

(28) $[$ gato meu $]\rceil=\{X: X=\|$ gato $]\rceil \cap \|$ meu $\|\}$

$\mathrm{O}$ fato de que sintagmas como gato meu podem funcionar como argumentos em certos contextos sintáticos é uma questão complexa que envolve a denotação dos nomes sem determinantes - os "bare N's" - no português brasileiro.

As soluções formais apresentadas nesta seção explicam como funciona a interpretação de um possessivo anteposto e posposto, tornando explícitas as idéias de seu papel delimitativo e predicativo. Estas soluções ainda nos deixam com certos problemas a resolver: (i) como explicar a diferença de comportamento de um mesmo item lexical - o pronome possessivo - se- 
Revisla da ANPOLL, n" 4, p. 11-37, jan./jun. 1998

gundo sua posição no sintagma nominal, ou seja, como as diferentes posições sintáticas se relacionam às diferentes interpretações do pronome e (ii) como explicar a possibilidade de uso do artigo definido com o pronome possessivo anteposto, ou seja, porque neste caso o artigo definido scria "redundante" ou funcionaria como um mero expletivo.

\section{A SINTAXE DA ORDEM DOS PRONOMES POSSESSIVOS NO SINTAGMA NOMINAL}

Mas, apesar de seu papel delimitador quando anteposto ao nome, não se pode dizer que sempre que temos uma estrutura $\mid$ Poss $|\mathrm{N}| \mid$ ocorre uma incorporação do significado do artigo definido ao pronome possessivo.

O fato de que o pronome possessivo anteposto ao nome não absorve o artigo definido pode ser ilustrado por contextos que não accitam descrições definidas, nos quais apenas o pronome possessivo sem artigo pode ocorrer no sintagma nominal: o uso vocativo, o uso predicativo e em construções como... ${ }^{16}$. A ausência necessária do artigo no uso vocativo em (29) mostra que um sintagma nominal com o pronome possessivo anteposto, não é sempre equivalente a uma descrição definida. O contraste entre (30) (a) e (b), onde a presença do artigo impede a atribuição do mesmo predicado a duas entidades, mostra que o pronome possessivo anteposto não carrega a implicação de unicidade do artigo definido. (31) (a) e (32) (a) mostram também que o sintagma nominal com um pronome possessivo anteposto não possui necessariamente uma interpretação existencial. Veja que as sentenças correspondentes em (b) só seriam gramaticais sob uma interpretação referencial do predicado secundário.

16 Os exemplos são adaptados de Declerck (1986) onde o ohjetivo da autora é discutir o uso do artigo definido em construçốes predicativas. 
(29) a. Meu filho! Venha cá!

b. * O meu filho! Venha cá!

(30) a. Jorge é meu amigo e Carlos também

b. *Jorge é o meu amigo e Carlos também

(31) a. Eu considero Carlos meu inimigo

b. ? Eu considero Carlos o meu inimigo

(32) a. Eu vim aqui como seu amigo

b. ?Eu vim aqui como o seu amigo

Nesse sentido, o comportamento de $[\mathrm{Poss}|\mathrm{N}| \mid$ é semelhante ao dos nomes próprios no Português do Brasil, pois estes também podem ocorrer com ou sem artigo na maioria dos contextos. No entanto, em contextos semelhantes aos exemplificados acima - vocativo, predicativo e aposto - o nome próprio também não accita o artigo, como ilustram (33)-(35).

(33) a. Jorge! Venha cá!

b. *O Jorge! Venha cá!

(34) a. Jorge pensa que é Napoleão

b. * Jorge pensa que é o Napoleão

(35) a. O Presidente, nosso colega Fernando Henrique Cardoso, visitará a USP cm 1997

b. * O Presidente, nosso colega o Fernando I Ienrique Cardoso, visitará a USP em 1997

Em ambos os casos, nesses contextos, tanto nomes próprios quanto |Poss |N|| comportam-se como se não incorporassem um determinante, o que parece indicar que sua categoria oscila entre Nome e Sintagma de 
Revista da ANPOLL, n" 4, p. 11-37, jan./jun. 1998

Determinante. Em posições argumentais comportam-se como sintagmas de determinantes plenos e, em posições predicativas, como simples nomes. $\mathrm{Ou}, \mathrm{em}$ termos semânticos: às vezes funcionam como se denotassem propriedades e às vezes como se denotassem indivíduos.

Longobardi (1994) estuda o comportamento dos constituintes nominais do italiano nos quais um determinante não está fonologicamente presente - os "bare nouns". A primcira observação do autor, a qual parece valer também para o português, é a de que um constituinte nominal com um núcleo singular contável não pode, de mancira geral, ocorrer em posições como as de sujeito, objeto direto e objeto indireto, as quais são posições típicas de argumentos. Este ponto está ilustrado nos exemplos ${ }^{17} \mathrm{em}$ (36). A mesma restrição não se coloca para constituintes nominais $\mathrm{cm}$ função não argumental, como as de vocativo, de predicativo c contextos de exclamação, como ilustrados em (37).

(36) a. * $\mid$ Crande amigo de Maria| me telefonou ontem

b. *Ontem eu encontrei |grande amigo de Marial

c. *Ontem conversei com |grande amigo de Maria|

(37) a. Querido filho, que bom te ver!

b. Carlos é professor

c. Maldito prefeito!

Mais ainda, é a presença de dois determinantes que impóe uma denotação plural a (38) (b) e não o número de sintagmas nominais presentes, pois (38) (b) só pode ser semanticamente interpretada como afirmando a existência de dois indivíduos, ao contrário de (38) (a).

(38) a. A minha secretária c tua colaboradora está/estão saindo b. A minha secretária e a tua colaboradora * está/estão saindo

17 Os exemplos (36)-(38) são adaptados de Longohardi (1994). 
MÜLLLER, Ana I ácia. () significado da ordem dos pronomes possessivos no sinlagma nominal.

A primeira generalização empírica para descrever estes fatos seria a de que um constituinte nominal só pode ser um argumento se for introduzido por um determinante lexicalmente preenchido. Esta observação, no entanto, não é genérica o suficiente, uma vez que é empiricamente falsificada por sentenças como (39) (a) e (b), onde o constituinte nominal é um nãocontável ou é um nome plural com uma interpretação de espécie.

(39) a. A cozinheira vai fazer carne para o jantar b. Carlos come sempre cerejas de sobremesa

Longobardi explica estes fatos para o italiano através da hipótese de que, quando ocupam posições argumentais, constituintes nominais com determinantes lexicalmente não preenchidos são Sintagmas de Determinante, só que com determinantes expletivos. A ocorrência desse tipo de Sintagma de Determinante em estrutura-S é restrita a nomes com interpretação de espécic ou não-contáveis aos quais é atribuída uma interpretação existencial default ${ }^{18}$. O licenciamento desses sintagmas com o determinante vazio depende da existência de regência lexical, como o licenciamento de qualquer outra categoria vazia. Com estes "provisos" o autor vai propor que um constituinte nominal é um argumento apenas se introduzido pela categoria Determinante.

Longobardi conclui chamando a atenção para a natureza crucial da categoria Determinante para as posições argumentais. Não vou tentar solucionar essa questão que envolve um estudo dos bare N's no português brasilciro e envolve a explicação de por que o determinante é necessário $\mathrm{em}$ alguns casos para sintagmas nominais em posições argumentais, como cm (40), c cm outros não o é, como cm (41).

18 Para o italiano, esta interpretação existencial seria semelhante à do artigo indelinido, com a diferença de estar submetida sempre a um narrou scope constrainl e ser indeterminada en relacão ao número semântico do sintagma nominal. A determinação do quanto estas generalizaçōes são válidas para o português exige um estudo mais aprofundado. 
Revisla da ANPOLL, n" 4, p. 11-37, jan./jun. 1998

(40) a. Ontem eu encontrei um grande amigo meu b. * Ontem eu encontrei grande amigo meu

(41) a. Naquele supermercado encontrci a carne de carneiro que procurava

b. Naquele supermercado encontrei carne de carneiro

No caso de [Poss $[\mathrm{N}||$ e dos nomes próprios, a redundância com o artigo definido me parece ser derivada do fato de que, mesmo que consideremos que sua categoria sintática é inicialmente Nome e que, posteriormente, conforme a estrutura em que é inserido, pode funcionar como um Sintagma de Determinante, o conjunto denotado por um $[$ Poss $|\mathrm{N}|]$ ou por um nome próprio contém um elemento dêitico, o que o torna indistingüível dos indivíduos membros desse conjunto e o faz cumprir o mesmo papel que um determinante - o de selecionar os membros de um conjunto sobre os quais se vai predicar.

Evidências sintáticas reforçam a diferença de função entre o pronome anteposto e o pronome posposto ao núcleo nominal. Os exemplos (42) e (43) mostram que apenas o pronome posposto aceita a modificação por um advérbio.

(42) a. Lá cu tinha um jardim gostosamente meu ${ }^{19}$ b. * Lá eu tinha um gostosamente meu jardim

(43) a. Jorge fez uma daquelas intervenções bem suas b. * Jorge fez uma daquelas bem suas intervenções

19 Exemplos de Franchi (1996). Casos como (i) não são contra-exemplos, porque, como mostra a possibilidade de posposição do possessivo em (i), o modificador se aplica a todo o sintagma e não apenas ao possessivo.

(I) $\Lambda$ Argélia, próxima c ainda nossa colônia.

(I) *` Argélia, próxima e ainda colônia nossa. 
MÜLLER, Ana Lúcia. O significado da ordem dos pronomes possessivos no sintagma nominal.

Nesse caso, o comportamento dos possessivos é is uma vez semelhante ao dos adjetivos que só aceitam modificações de segunda ordem quando pospostos, como ilustrado em (44) e (45).

(44) a. Lá cu tinha um jardim bem antigo

b. * Lá eu tinha um bem antigo jardim

(45) a. Jorge fez uma daquelas intervenções bem divertidas b. *Jorge fez aquela bem divertida intervenção

Mais uma evidência do caráter distinto das duas posições do pronome possessivo vem da possibilidade de coordenação de um adjetivo e um pronome possessivo que se restringe ao pronome possessivo posposto, como mostra o exemplo em (46) (a). O exemplo em (b) mostra a impossibilidade de coordenação entre um possessivo e um adjetivo antepostos.

(46) a. Foi uma vitória gerativista e minha quando o grupo de Teoria Gramatical conseguiu as primeiras classificações no concurso de monografias

b. *Foi uma grande e minha vitória quando o grupo de Teoria Gramatical conseguiu as primeiras classificações no concurso de monografias

A hierarquia temático-estrutural possessivo $>$ agente/experienciador $>$ tema, que é obedecida para a interpretação do pronome anteposto (esta hierarquia está ilustrada em (47)), não se aplica ao pronome posposto. A interpretação do pronome possessivo posposto não obedece a qualquer hierarquia, como se pode ver em (48)-(50). (48) mostra que, como o possesivo anteposto, o pronome posposto pode receber todas as interpretações "genitivas". Ao incluirmos um agente explícito cm (49), as interpretações tanto de tema quanto de posse continuam disponíveis ao pro- 
nome, ao contrário do caso com o pronome anteposto, para o qual apenas a interpretação de tema seria possível. O mesmo tipo de fenômeno ocorre cm (50), onde a ocorrência de um genitivo possuidor explícito não impede a interpretação do pronome como tema ou agente.

(47) a. a minha ${ }_{\text {AGENTE/TEMAPOSSUIDOR }}$ foto

b. a minha ${ }_{\text {ACENTE/*TENAPOSSUIDOR }}$ foto [de Luiza Brunet]

c. a minha ${ }_{* \text { ACENTE/*TEMINOSSUIDOR }}$ foto |do colecionador|

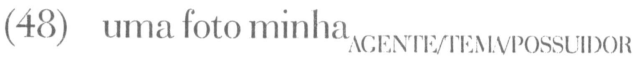

(49) uma foto minha $a_{\text {TEMnPossissiro }} \mid$ de David Zing $\left.\right|_{\text {ACENTE }}$

(50) uma foto minha $\mid$ do colecionador $\left.\right|_{\text {POSSUIDOR }}$

Vemos então que, além de possuir um caráter semântico diferente, o pronome possessivo anteposto difere em seu comportamento sintatico do possessivo posposto. O pronome posposto ocupa provavelmente a mesma posição estrutural dos adjetivos pospostos, ou seja, é um adjunto do núcleo nominal.

\section{CONCLUSÃO}

O trabalho mostra que tanto as propriedades sintáticas quanto as propriedades semânticas do pronome possessivo são bastante distintas dependendo quando este se encontra anteposto ou posposto ao núcleo nominal. Müller (1997 e no prelo) mostrou que, quando anteposto, o possessivo é um argumento do nome com a função sintática de sujeito do sintagma nominal. Este trabalho mostra que, quando posposto, o pronome é um predicado sobre o núcleo nominal com a função sintática de adjunto. 
MÜLLER, Ana Lúcia. O significado da ordem dos pronomes possessivos no sintagma nominal.

Este trabalho também argumenta que o caráter delimitador do pronome possessivo anteposto não decorre de uma incorporação de um determinante definido. $\mathrm{O}$ fato de que o possessivo anteposto é um elemento dêitico em uma função argumental, faz com que a denotação do sintagma nominal ao qual pertence selecione um conjunto composto de elementos do contexto imediato e este conjunto é indistingüível dos elementos que o compõem. Essa ação delimitadora torna o artigo definido quase que redundante e os indefinidos quase que incompatíveis.

ABSTRACT:This article deals with the semantic differences caused by the anteposition or postposition of the possessive pronoun in relation to the head noun. It also deals with its semantic and syntactic roles in these positions. The hypothesis is that the different positions of the possessive pronoun are related to different syntactic and semantic functions: the anteposed possessive is an argument. (syntaclically: a subject or a complement), and the postposed pronoun is a predicate. (synlactically: an adjunct).The article also argues that the delimitaling character of the anteposed possessive pronoun does not follow from an incorporation of a definile determiner: The fact that the anteposed possessive is a deictic element in an argumental function makes the denotation of the noun phrase to which il belongs select a set composed of entities from the imediate context and this set is indistinguishable from its elements. This fact makes the definite arlicle almost redundanct and indefinite determiners almost incompatible with the anteposed possessive pronoun.

KEYWORDS: possessives; noun phrase; synlax; semantics.

\section{BIBLIOGRAFIA}

BACI I, E. (1989) Informal Lectures on Formal Semantics. Albany, NY:State University of New York Press.

BARWISE, J. \&. R. COOPER (1981) "Ceneralized Quantifiers and Natural Languages". Linguistics and Philosophy 4: 159-220. 
Revista da ANPOL/, n" 4, p. 11-37, jan./jun. 1998

BIERWISCII, M. |1970| (1971) "On classifying semantic features". IN: D.D. Steinberg \& I

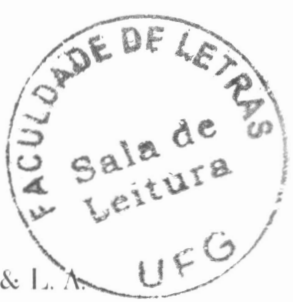
Jacohovits (eds.) Semantics: an Interdisciplinary Reader in Philosophy; Linguistics and Psychology: Cambridge:Cambridge University Press. pags. 410-4.35.

BORCES NETO, J. (1978) "Os papéis do possessivo no sintagma nominal". Estudos Lingüísticos: Ancuis de Seminários do CEL 2: 62-69.

CASTILIIO, A. (1990) (org.) Gramálica do Porluguês Falado, vol. 1. Campinas:Editora da UNICAMP/FAPESP.

CASTII I IO, A. \&. D. PRETI (1986) A Linguagem Fàlada Culta na Cidade de São Paulo: Elocuções Formais, vol 1. SP: Qucirós/FAPESP.

DECLERCK, R. (1986) "Tiwo Notes on the Theory of Definiteness".Journal of Linguislics 22: 25-39.

FRANCIII, C. (1996) "Anotações", (manuscrilo).

LONCOBARDI, C. (1994) "Reference and Proper Names: $\Lambda$ Theory of N-Movement in Syntax and I.ogical Form". Linguistic Inquiry, 25(4): 609-66.5.

MüldLER, A.L. (1997) "A Gramática das Formas Possessivas no Português do Brasil". Tese de doutorado inédita, IEI/UNICAMP.

(no prelo) "A estrutura do sintagma nominal com argumentos genitivos". Cadernos de Estudos Lingüísticos 31. Publicações IEI/UNICAMP.

PERES, J.A. (1991) "Basic Aspects of the Theory of Ceneralized Quantiliers". In: Figuciras,M. et al. (orgs). Natural Language Processing EAEA'90, 2nd Advanced School in Artificial Intelligence, Guarda Porlugal, Oclober 1990, Proceedings Springer-Verlag, Berlim:141-157.

NEVES, M.II.M. (1993) "Possessivos". IN: CASTII I IO, A.T. (org.) Gramálica do Português Falado, vol.3. Campinas: Editora da UNICAMP/FAPESP, págs. 149-211. 